\title{
LITERATURE REVIEW : GAMBARAN KEPUASAN PASIEN DALAM PELAYANAN KEPERAWATAN DI RUMAH SAKIT
}

\author{
Literature Review: Description Of Patient Satisfaction In Nursing Services At The Hospital
}

\author{
Aries Wahyuningsih, Srinalesti Mahanani, Septi Arum Pradana \\ STIKES RS Baptis Kediri (aries.wahyuningsih@gmail.com)
}

\section{ABSTRACT}

Background: The unequal distribution of employment by level of education is a problem in itself. Most of the service institutions in Indonesia also have not developed a career path for nurses, so the pattern of reward and welfare of nurses will affect performance. Nursing services as health service providers so that satisfaction is the main goal in providing quality services.

Purpose: This study aims to explain the description of nursing service satisfaction based on a literature review. This research used literature study.

Method: The literature obtained from the use of PubMed, and Google Scholar and 10 literature reviews were analyzed by PICO.

Result: The results of the research from the literature review showed that 7 journals $(70 \%)$ patients were less satisfied and only 3 journals (30\%) patients were satisfied with nursing services based on Community Satisfaction Index standards of hospital.

Conclusion: Patient Satisfaction in Nursing Services From various literature review results found that the majority stated that they were not satisfied with nursing services.

Key Word: Satisfaction; Patient Satisfaction; Nursing Services

\section{ABSTRAK}

Latar belakang: Belum meratanya distribusi ketenagaan yang berdasarkan tingkat pendidikan menjadi permasalahan tersendiri. Sebagian besar institusi pelayanan di Indonesia juga belum mengembangkan jenjang karir perawat, sehingga pola penghargaan dan kesejahteraan tenaga keperawatan akan berpengaruh pada kinerja. Pelayanan keperawatan sebagai pemberi jasa pelayanan kesehatan sehingga kepuasan merupakan tujuan utama dalam memberikan pelayanan yang berkualitas

Tujuan: Penelitian dari literatur review ini bertujuan untuk Menjelaskan Gambaran Kepuasan Pelayanan Keperawatan berdasarkan hasil review literature.

Metode : Penelitian ini menggunakan Study Literatur review. Literatur yang didapatkan dari menggunakan PubMed,Google Scholar dan 10 literatur review dilakukan analisa PICO.

Hasil: Hasil yang dikumpulkan menunjukkan bahwa dari 10 litertur review didapatkan adanya hasil 7 jurnal (70\%) pasien kurang puas dan hanya 3 jurnal (30\%) pasien puas terhadap pelayanan keperawatan berdasarkan standar IKM RS.

Kesimpulan: Kepuasan Pasien dalam Pelayanan Keperawatan dari berbagai hasil literatur review penelitian didapatkan bahwa Mayoritas menyatakan Kurang Puas terhadap Pelayanan Keperawatan

Kata kunci: Kepuasan Pasien; Pelayanan Keperawatan; Kepuasan Pelayanan Keperawatan

\section{PENDAHULUAN}

Sebagian besar tatanan pelayanan kesehatan asuhan keperawatan, masih terbatas melakukan kegiatan-kegiatan yang belum memenuhi kaidah asuhan keperawatan secara 
profesional yang bertanggung jawab. Hal ini berdampak pada mutu pelayanan keperawatan yang optimal. Belum meratanya distribusi ketenagaan yang berdasarkan tingkat pendidikan juga juga menjadi permasalahan tersendiri. Sebagian besar institusi pelayanan di Indonesia juga belum mengembangkan jenjang karir perawat, sehingga pola penghargaan dan kesejahteraan tenaga keperawatan akan berpengaruh pada kinerja (Sumijatun, 2009).

Pelayanan keperawatan sebagai pemberi jasa pelayanan yang berkualitas sehingga kepuasan merupakan tujuan utama (Syah, 2014). Pelayanan Keperawatan di Rumah Sakit Baptis Kediri dilihat dari data IKM RS Rumah Sakit Baptis Kediri pada semester dua mengalami penurunan.

Berdasarkan hasil penelitian yang dilakukan (Anam \& Kusna, 2012) menenentukan kepuasan pasien yang dilakukan di Rumah Sakit DKT Mojokerto yang dilakukan pada 10 orang yang rawat inap pada tanggal 5 Januari 2011 terdapat 8 orang yang menyatakan kurang puas terhadap pelayanan perawat dan 2 orang menyatakan sangat puas terhadap pelayanan perawat pada saat dirawat di rawat inap di Rumah Sakit DKT Mojokerto. Hasil prapenelitian pada pasien rawat inap di Rumah Sakit Umum Daerah (RSUD) Bangkinang Kota Kabupaten Kampar melalui 25 pasien rawat inap mengeluhkan belum puas terhadap pelayanan perawatan yang ada di rumah sakit. Sebanyak 52\% pasien mengeluh pada aspek perhatian, $72 \%$ pasien mengeluh pada aspek penerimaan, $76 \%$ pasien mengeluh pada aspek komunikasi, $60 \%$ mengeluh pada aspek kerjasama, dan 64\% pasien mengeluh pada aspek tanggung jawab.

Berdasarkan hasil pra penelitian yang didapat dari data sekunder IKM RS Rumah Sakit Baptis Kediri pada yang didapat dari Komite Keperawatan Rumah Sakit Baptis Kediri tahun 2019 periode semestrer 1 pada bulan Januari-Juni 2019 diketahui hasil kepuasan di Ruang Anak Karunia (86,12\%), sedangkan periode semester 2 pada bulan Juni- Desember 2019 diketahui kepuasan di Ruang Anak Karunia (80,17\%). Dari hasil tersebut didapatkan kepuasan pasien terhadap pelayanan keperawatan mengalami penurunan.

Pelayanan kepada pelanggan kadang-kadang tidak sesuai dengan harapan sehingga mengakibatkan kegagalan yaitu perbedaan antara harapan pelanggan dengan prinsip manajemen, perbedaan antara persepsi manajemen dengan spesifikasi mutu jasa, perbedaan antara spesifikasi mutu jasa dan penyampaian jasa, perbedaan antara penyampaian jasa dan komunikasi eksternal, perbedaan antara jasa yang dialami dan jasa yang diharapkan (Susetyo, 2016).

Unit pelayanan di rumah sakit memberikan pelayanan secara konperhensif untuk membantuu menyelesaikan masalah yang di alami oleh pasien, dimana unit rawat inap 
merupakan salah satu revenew center rumah sakit sehingga tingkat kepuasan pelanggan atau pasien bisa dipakai sebagai salah satu indikator mutu pelayanan (Rochfika, 2019). Elemen kepuasan konsumen merupakan yang terpenting. Jika konsumen tidak puas dengan mutu pelayanan yang diberikan, pasien tidak akan kembali atau mencari layanan lainnya, walaupun layanan tersebut tersedia, mudah didapat dan mudah dijangkau (Susetyo, 2016). Pasien akan merasa puas apabila kinerja pelayanan yang diperolehnya sama atau melebihi dari apa yang menjadi harapannya dan sebaliknya, ketidakpuasan akan timbul atau perasaan kecewa pasien akan terjadi apabila kinerja pelayanan kesehatan yang diperolehnya itu tidak sesuai dengan harapannya (Pohan,2015)

Kepuasan pasien tergantung kesesuaian antara produk jasa yang diberikan dengan harapan pembeli produk tersebut. Pelanggan akan merasa puas jika pelayanan yang diterima sama atau lebih dari harapan. Sebaliknya, pasien merasa kecewa jika pelayanan yang diterima masih dibawah harapan ( Maria, 2017). Kepuasan seorang pelanggan tergantung kesesuaian antara prestasi produk dengan harapan pembeli produk tersebut. Pelanggan merasa puas jika pelayanan yang diterima minimal sama atau lebih dari harapan. Sebaliknya, pelanggan merasa kecewa jika yang diterima masih dibawah harapan (Bakhri, 2017). Peneliti melakukan literature riview tentang "Gambaran Kepuasan Pasien dalam Pelayanan Keperawatan di Rumah Sakit".

Bagian ini berisi mengenai latar belakang, konteks penelitian, hasil kajian pustaka serta tujuan penelitian. Seluruh bagian dari pendahuluan diintegrasikan menjadi paragraph-paragraf dan mencangkup 15-20\% dari total artike

\section{METODE PENELITIAN}

Review ini bertujuan untuk untuk menjelaskan gambaran kepuasan pelayanan keperawatan berdasarkan hasil review literature. Peneliti melakukan review dengan berbagai desain penelitian yaitu Descriptive Survei, Kuantitatif Deskriptif dan Descriptive Cross sectiona yang berhubungan dengan tujuan penelitian. Jurnal yang dipakai dari tahun 2010-2020. Sumber Sumber database online yang digunakan berasal dari repositori menggunakan bahasa Indonesia atau bahasa Internasional. Jumlah referensi yang digunakan dalam literature review ini adalah 10 artikel utama fulltext. Populasi pada pasien pasien yang bersedia dijadikan responden, semua pasien yang di rawat inap, dapat membaca dan menulis. 


\section{HASIL PENELITIAN}

Peneliti mendapatkan total penelitian sebanyak 10 artikel penelitian sesuai dengan kriteria inklusi. studi penelitian yang sesuai dengan kriteria diantaranya ((Valentina dkk, 2017), (Oini \& Komalasari, dkk. 2017), (Arifin \& Sumitri, dkk. 2013), (Librianty. 2019), (Anam \& Kusnia, dkk 2012.), (Budiana \& Londa, dkk. 2019), (Novitasari \& Hidayat, dkk. 2014), (Frida \& Putri, 2019), (Neami \& Dimabayao, dkk. 2014), (Ozlul \& Ozer dkk. 2010)). Peneliti melakukan strategi pencarian literatur dengan menggunakan sistem pencarian menggunakan bahasa Indonesia dan bahasa inggris dengan menggunakan search string dan sumber database elektronik Google scholar, SINTA, Pubmed dan Scopus. Peneliti menggunakan metode pencarian menggunakan Google scholar dengan mencari literatur jurnal berdasarkan tujuan penelitian "Menjelaskan gambaran kepuasan pelayanan keperawatan" dalam Bahasa Indonesia dengan kata kunci "Kepuasan [dan] Pelayanan Keperawatan” dan dalam Bahasa Inggris menggunakan kata kunci "Patient Satisfaction; [And]; Nursing Services" Hasil pencarian awal dengan system pencarian menggunakan google scholar didapatkan hasil 16.100 data, PubMed didapatkan 4.459 data.

Karakteristik berdasarkan design yang sama didapatkan 4 jurnal menggunakan design Descriptif survei, pada jurnal dengan penulis (Sari \& Susanti, dkk. 2017); (Anam \& Kusnia, dkk. 2012), (Novitasari \& Hidayat, dkk. 2014) 2 jurnal menggunakan design Descriptif, pada jurnal dengan penulis (Arifin \& Sumitri, dkk. 2013); (Ozlul \& Ozer , dkk. 2010), 1 jurnal menggunakan design Kuantitatif Deskriptif, pada jurnal dengan penulis (Oini \& Komalasari, dkk. 2017),), 1 jurnal menggunakan design Deskriptive Cross Sectional, pada jurnal dengan penulis (Neami \& Dimabayo, dkk. 2014), 1 jurnal menggunakan design Deskriptif Korelasi, pada jurnal (Frida \& Putri, 2019) dan 1 jurnal menggunakan design Analitik Cross Sectional, pada jurnal (Librianty, 2019) untuk memaparkan kepuasan pasien terhadap pelayanan keperawatan.

Karakteristik berdasarkan alat ukur 10 jurnal yang didapatkan, semua jurnal menggunakan alat ukur kuesioner untuk mengukur kepuasan pelayanan keperawatan. Pada jurnal dengan penulis (Sari \& Susanti, dkk. 2017) menggunakan alat ukur kuesioner baku tentang kepuasan pasien berdasarkan lima karak-teristik (RATER), (Oini \& Komalasari,dkk. 2017) menggunakan alat ukur kuesioner Service Quality (SERQUAL), (Arifin \& Sumitri, dkk. 2013) menggunakan alat ukur kuesioner dari fasilitas jamkesmas dan non jamkesmas, (Librianty. 2019) menggunakan alat ukur kuesioner yang dibuat dari data primer umur, 
pendidikan terakhir, jenis kelamin dan pekerjaan, (Anam \& Kusnia, dkk. 2012) menggunakan alat ukur kuesioner 5 dimensi kualitas layanan penentu tingkat kepuasan pasien yaitu Reliability, Insurance, Tangiable, Emphaty, Responsiveness

(Budiana \& Londa, 2019) menggunakan alat ukur kuesioner yang dibuat berdasarkan data primer umur, tingkat pendidikan, perawatan luka, pekerjaan, kebersihan individu dan pelayanan keperawatan, (Novitasari \& Hidayat, dkk. 2014) menggunakan alat ukur kuesioner dimensi pelayanan tangible, reliability, responsiveness, assurance, dan emphaty berdasarkan usia, pendidikan, dan pekerjaan, (Frida \& Putri, 2019) menggunakan alat ukur kuesioner dengan menggunakan skala Liker, (Neami \& Dimabayao, dkk. 2014),) menggunakan alat ukur Satisfaction with Care - SF, (Ozlul \& Ozer, dkk. 2010) menggunakan alat ukur kuesioner bentuk data demografis dan skala PPHEN.

Karakteristik berdasarkan besar sampel, jurnal dengan penulis (Sari \& Susanti, dkk. 2017) menggunakan besar sampel 86 responden, (Oini \& Komalasari, dkk. 2017 menggunakan besar sampel 135 responden, ( Arifin \& Sumitri, dkk. 2013) menggunakan besar sampel 74 responden, (Librianty, 2019) menggunakan besar sampel 95 responden, (Anam \& Kussna, dkk. 2012.) menggunakan besar sampel 35 pasien dan 35 keluarga pasien sebagai responden, (Budiana \& Londa. 2019)) menggunakan besar sampel 248 responden, (Novitasari \& Hidayat, dkk. 2014) menggunakan sampel 70 responden, (Frida \& Putri, dkk. 2019) menggunakan besar sampel 60 responden, (Neami \& Dimabayao, dkk, 2014) menggunakan besar sampel 148 responden, (Ozlul \& Ozer, dkk. 2010) menggunakan besar sampel 128 responden.

Karakteristik berdasarkan sampling yang digunakan, metode besar sampling yang digunakan 1 menggunakan nonprobability sampling, 2 jurnal menggunakan purposive sampling, 3 jurnal menggunakan accidental sampling, 1 jurnal menggunakan Consecutive sampling, 2 jurnal menggunakan Total Sampling, , 1 jurnal tidak memiliki keterangan teknik pengambilan sampling.

Hasil studi literatur review didapatkan bahwa kepuasan pasien dalam pelayanan keperawatan bervariasi pada setiap penelitian yang telah di review. Hasil analisa pengetahuan perawatan kaki sangat beragam antara lain : (Sari \& Susanti, dkk. 2017) puas (36\%), sangat puas (64\%), (Oini \& Komalasari dkk. 2017) puas (54,52\%), ( Arifin \& Sumitri dkk. 2013) puas $(54,10 \%)$, kurang puas $(45,90 \%)$, (Librianty dkk. 2019) puas (40\%), kurang puas (60\%), (Anam \& Kusnia, dkk, 2012) puas (51,40\%), kurang puas (48,60\%), (Budiana \& Londa. 2019) puas (12\%), cukup puas (60\%), kurang puas (28\%), (Andra dkk. 2014) puas (54,10\%), kurang 
puas $(45,90 \%)$, (Frida \& Putri, 2019) puas (26,7\%), kurang puas $(73,3 \%)$, (Neami \& Dimabayao, dkk. 2014) puas (3,20), dan (Ozlul \& Ozer dkk. 2010) puas (70,10\%).

\section{PEMBAHASAN}

\section{Menjelaskan gambaran kepuasan pelayanan keperawatan berdasarkan hasil review literature.}

Hasil studi literatur review didapatkan bahwa kepuasan pasien dalam pelayanan keperawatan bervariasi pada setiap penelitian yang telah di review. Hasil analisa pengetahuan perawatan kaki sangat beragam antara lain : pada penelitian (Sari \&Susanti, dkk, 2017), (Oini \& Komalasari, dkk, 2017), (Arifin \& Sumitri, dkk. 2013), (Librianty, 2019), (Anam \& Kusna dkk. 2012.), (Budiana \& Londa. 2019), Novitasari \& Hidayat,dkk. 2014, (Frida \& Putri, 2019), (Neami \& Dimabayao, dkk. 2014), (Ozlul \& Ozer dkk. 2010) memiliki hasil bahwa kepuasan pasien terhadap pelayanan keperawatan bervariasi. Hasil artikel dengan penulis (Sari dkk. 2017) puas (36\%), sangat puas (64\%), artikel dengan penulis (Ozlul \& Ozer dkk. 2010) puas (3.20), artikel dengan penulis (Ozlul \& Ozer dkk. 2010) puas (70,10\%), artikel dengan penulis (Oini \& Komalasari, dkk. 2017) puas (54,52\%), artikel dengan penulis (Arifin \& Sumitri, dkk. 2013 ) puas $(54,10 \%)$, kurang puas $(45,90 \%)$, artikel dengan penulis (Anam \& Kusnia, dkk. 2012.) puas $(51,40 \%)$, kurang puas $(48,10 \%)$, artikel dengan penulis (Budiana \& Londa. 2019) puas (12\%), cukup puas (60\%), kurang puas (28\%), artikel dengan penulis (Novitasari \& Hidayat, dkk. 2014) puas (54,10\%), kurang puas (45,90\%), artikel dengan penulis (Librianty, 2019) puas (40\%), kurang puas (60\%), dan artikel dengan penulis (Frida \& Putri, 2019) puas $(26,7 \%)$, kurang puas $(73,3 \%)$. Berdasarkan kajian IKM RS ada 7 jurnal (70\%) pasien kurang puas dan hanya 3 jurnal (30\%) pasien puas terhadap pelayanan keperawatan.

Kepuasan adalah model kesenjangan antara harapan (standar kinerja yang seharusnya) dengan kinerja aktual yang diterima pelanggan. Adapun Faktor-Fakktor yang mempengaruhi kepuasan pasien yaitu Kualitas Produk atau Jasa, Harga, Emosional, Kinerja, Estetika, Karakteristik Produk, Pelayanan, Lokasi, Fasilitas, Komunikasi, Suasana, dan Desain Visual (Nursalam, 2016).

Kepuasan Pasien memiliki standar untuk menilai suatu hasil yang disebut dengan IKM RS (Indeks Kepuasan Masyarakat Rumah Sakit). Kinerja unit pelayanan dikatakan Tidak Baik dengan Nilai Interval Indeks Kepuasan Masyarakat (1,00-1,77) dan Nilai Interval Konverensi Indeks Kepuasan Masyarakat (25-43,75), Kinerja unit pelayanan dikatakan Kurang Baik dengan Nilai Interval Indeks Kepuasan Masyarakat $(1,76-2,50)$ dan Nilai Interval Konverensi Indeks Kepuasan Masyarakat (43,76-62,50), Kinerja unit pelayanan dikatakan Baik dengan 
Nilai Interval Indeks Kepuasan Masyarakat (2,51-3,25) dan Nilai Interval Konverensi Indeks Kepuasan Masyarakat $(62,51-81,25)$, dan Kinerja unit pelayanan dikatakan Sangat Baik dengan Nilai Interval Indeks Kepuasan Masyarakat $(3,26-4,00)$ dan Nilai Interval Konverensi Indeks Kepuasan Masyarakat (81,26-100,00) (Indeks Kepuasan Masyarakat RS dr. Sutomo Surabaya dikutip dari data IKM RS Rumah Sakit Baptis Kediri, 2019).

Kepuasan pasien adalah nilai subyektif pasien terhadap pelayanan keperawatan yang diberikan dari kesan pertama masuk rumah sakit. Banyak faktor yang dapat mempengaruhi kepuasan pasien salah satunya yaitu pelayanan sehingga rumah sakit perlu memberikan kualitas pelayanan keperawatan yang baik dalam memenuhi kebutuhan pasien. Pada saat ini banyak sekali hal yang mengakibatkan tidak puasnya pasien terhadap pelayanan keperawatan beberapa hal tersebut antara lain pelayanan keperawatan yang kurang baik, kurang maksimalnya kolaborasi perawat dengan pasien, ketanggapan perawat yang kurang, kurangnya perawat dalam menyampaikan informasi tentang kondisi pasien, dan lama respon perawat terhadap keluhan pasien.

Hal tersebut dapat ditanggulangi dengan cara BHSP (Bina Hubungan Saling Percaya) yang merupakan dasar perawat dapat lebih dekat dengan pasien sehingga mampu memantau dengan cepat masalah yang terjadi pada pasien dan tanggap untuk memberikan perawatan yang sesuai. Perawat diharapkan lebih profesional serta memberikan pelayanan dengan sepenuh hati dan selalu bersikap ramah. Perawat juga harus memperhatikan semua tindakan-tindakan yang berhubungan langsung dengan pasien, semua tindakan harus dilakukan sesuai dengan prosedur yang sudah ditetapkan, karena setiap tindakan yang dilakukan perawat adalah untuk menjaga pasien selama menjalani perawatan di Rumah Sakit.

Selain itu perawat perlu meningkatkan pengetahuan dan ketrampilan tentang pelayanan keperawatan sesuai jenjang kompetensi dan tanggungjawabnya. Penelitian kepuasan pasien dalam pelayanan keperawatan yang di riview menggunakan alat ukur kuesioner yang berbeda beda yaitu SERQUAL, kuesioner yang dibuat dari data primer, kuesioner RATER, skala PPHEN, kuesioner yang mudah digunakan salah satunya kuesioner RATER dengan menggunakan uji validitas univariat. Berdasarkan hasil dari 10 jurnal literatur review yang didapatkan mayoritas kepuasan pasien terhadap pelayanan keperawatan kurang baik (70\%) dan hanya $(30 \%)$ kepuasan pasien terhadap pelayanan keperawatan baik dilihat berdasarkan standar IKM RS. 


\section{SIMPULAN DAN SARAN}

\section{Simpulan}

Gambaran Kepuasan Pasien dalam Pelayanan Keperawatan di Rumah Sakit dari hasil kesimpulan 10 litertur review didapatkan adanya hasil 7 jurnal (70\%) pasien kurang puas dan hanya 3 jurnal (30\%) pasien puas terhadap pelayanan keperawatan berdasarkan standar IKM RS. Kepuasan Pasien dalam Pelayanan Keperawatan dari berbagai hasil literatur review penelitian didapatkan bahwa Mayoritas menyatakan Kurang Puas terhadap Pelayanan Keperawatan.

\section{Saran}

\section{Bagi Responden}

Merekomendasikan untuk selalu meningkatkan derajat kepuasan pada pelayanan keperawatan.

\section{Bagi Rumah Sakit}

Bagi Rumah Sakit bisa dapat meningkatkan kualitas mutu pelayanan keperawatan ke arah yang lebih baik sehingga pasien akan merasa puas dengan jasa yang diberikan.

\section{Bagi peneliti selanjutnya}

Bagi peneliti selanjutnya bisa melakukan pengukuran yang lebih objektif dengan melakukan observasi secara langsung perbedaan persepsi perawat dan pasien terkait dengan pelayanan keperawatan dengan memperhatikan kelas perawatan pasien.

\section{DAFTAR PUSTAKA}

Anam A. \& Khusnia I., (2012). Tingkat Kepuasan Pasien Rawat Inap Dan Keluarga Pada Pelayanan Keperawatan Di Rumah Sakit DKT Mojokerto. Jurnal Ilmiah Kesehatan Politeknik Kesehatan Mojokerto. Vol. 4 No 2. http://garuda.ristekbrin.go.id/documents/detail/939397. Diakses pada tanggal 28 Mei 2020 pukul 15.00

Arifin M., Sumitri., Lestari Y., (2013). Tingkat Kepuasan Pasien Rawat Inap Terdapat PelayananKeperawatan. Jurnal Ilmiah Kesehatan . Vol. 5, No. 2. https://scholar.google.co.id/scholar?hl=id\&as_sdt=0\%2C5\&q=Gambaran+tingkat+kep uasan+pelayanan+keperawatan\&btnG $=$. Diakses pada tanggal 29 Januari 2020 pukul $22.30 \mathrm{WIB}$

Bakri Maria H, (2017). Manajemen Keperawatan: Konsep dan Aplikasi dalam Praktik Keperawatan Profesional. Yogyakarta: Pustaka Baru Press

Budiana I., Londa K.I, (2019). Tingkat Kepuasan Pasien Pada Pelayanan Keperawatan Di Ruang Rawat Inap RSUD Ende. Jurnal Kesehatan Primer. Volume 5 ,No. 2. Hal. : 98- 
106. $\quad$ https://jurnal.poltekeskupang.ac.id/index.php/jkp/article/download/347/222. Diakses pada tanggal 28 Mei 2020 pukul 15.00

Firda \& Putri (2019). Hubungan Pelayanan Keperawatan Dengan Kepuasan Pasien Bpjs Rawat Inap Di Rumah Sakit Umum Herna medan. Jurnal Dharma Agung Husada. Vol. 6, No 2 .

https://scholar.google.co.id/scholar?hl=en\&as_sdt=0\%2C5\&q=Hubungan+Pelayanan+Keper awatan+dengan+Kepuasan+Pasien+BPJS+Rawat+Inap+di+Rumah+Sakit+Umum+Her na+Medan\&btnG=. Diakses Pada tanggal 1 Juli 2020 Pukul 13.30

Herlambang Susatyo, (2016). Manajemen Pelayanan Kesehatan Rumah Sakit. Yogyakarta: Gosyen Publising

Librianty N.(2019). Hubungan pelayanan keperawatan dengan kepuasan pasien rawat inap di RSUDBangkinang kota. Jurnal Ners. Vol. 3, No. 2.

https://scholar.google.co.id/scholar?hl=en\&as_sdt=0\%2C5\&q=Hubungan+pelayanan + keperawatan+dengan+kepuasan+pasien+rawat+inap+di+rsud+bangkinang+kota+tahun $+2019+\&$ btnG $=$. Diakses pada tanggal 1 Juli 2020 pukul 13.15

Novitasari, Hidayat M., Kaporina (2014). Kepuasan Pasien Rawat Inap terhadap Pelayanan Keperawatan di RSUP Dr. Kariadi Semarang. Jurnal Kedokteran Muhammadiyah. Vol. 3, No.1 Diakses pada tanggal 28 Mei 2020 pukul 16.00

Nursalam, (2015). Metodologi Penelitian Ilmu Keperawatan: Pendekatan Praktik Edisi 4. Jakarta: Salemba Medika

Nursalam, (2016). Manajemen Keperawatan: Aplikasi Dalam Praktik Keperawatan Profesional, Edisi Keempat. Jakarta: Salemba Medika

Neami, Dimabayao, Caculitan (2014). . Satisfaction Level of Inpatients on the Nursing Care Provided By Staff Nurses at King Fahd Central Hospital. International Journal of Nursing and Health Science. Vol. 3.o. 2. Hal : 22-31. https://www.semanticscholar.org/paper/Satisfaction-Level-of-Inpatients-on-the-

Nursing-By-Neami Dimabayao/60ac2ee67df13c35f2f02e8f9e0ec29e60bdba29. Diakses pada tanggal 20 Juli 2020

Oini O., Komalasari R., Yuliana S. (2017). Tingkat Kepuasan Pasien Terhadap Pelayanan Keperawatan Di Unit Rawat Inap. Nursing Current. Vol. 5 no $2 .$. http://garuda.ristekbrin.go.id/documents/detail/1037429. Diakses tanggal 28 Mei 2020 pukul 13.35

Ozlul K.Z., Ozer K., Arslan, dkk, (2010). Satisfaction Of Patients Staying In Day Surgery Clinic From Nursing Services. Pakistan Journal of Medical Sciences. Vol. 26. No 2. Hal. 438-443. https://www.researchgate.net/profile/Sevban_Arslan/publication/264876382_Satisfacti on_of_patients_staying_in_day_surgery_clinic_from_nursing_services/links/5593cbaa 08ae1e9cb429d4d1/Satisfaction-of-patients-staying-in-day-surgery-clinic-fromnursing-services.pdf. Diakses pada tanggal 18 Juli 2020 pukul 09.00

Rochfika, (2019). Percutanius Coronary Intervention. Ponorogo: Uwais Inspirasi Indonesia Rumah Sakit Baptis Kediri, (2017). Pedoman Pelayanan Instalasi Rawat Inap.

Sari V.W., Susanti D., Wulandari. (2017). Gambaran Tingkat Kepuasan Pasien Rawat Inap kelas II Terdapat Pelayanan Keperawatan. Jurnal Riset Kesehatan Nasional. Vol.1, No.1. https://scholar.google.co.id/scholar?hl=id\&as_sdt=0\%2C5\&q=Gambaran+tingkat+kep 
uasan++Pasien+rawat+inap+kelas+II+TERHADAP+PELAYANAN+KEPERAWATA $\underline{N} \&$ btnG $=$. Diakses pada tanggal 29 Januari 2020 pukul $23.30 \mathrm{WIB}$

Sumiatun, (2009). Manajemen Keperawatan. Konsep Dasar dan Aplikasi Penngambilan Keputusan Klinis. Jakarta : Trans Info

Syah Candra P., (2014). Buku Ajar Manajemen Keperawatan. Bogor: IN MEDIA

Pohan Imbalo. ( 2015 ) Jaminan Mutu Layanan Kesehatan. Jakarta : EGC 